\title{
"It's such a vicious cycle": Narrative accounts of the sportsperson with epilepsy
}

\section{Introduction}

Epilepsy is "a chronic condition in which a person has recurrent seizures due to an underlying cerebral process" (Dubow \& Kelly, 2003, p.24). As one of the most common neurological disorders, epilepsy affects 50 per 100,000 people in the UK per year and 50 million people worldwide (Aydemir, Vu Trung, Snape, Baker, \& Jacoby, 2009). Research has shown physical activity to be beneficial for most people with epilepsy (PWE) because of its positive effects on seizure control and personal well-being (Pimental, Tojal \& Morgado, 2015). However, PWE experience many barriers to exercising with epilepsy. First, as the medical community have not reached a consensus about the benefits and promotion of exercise, many PWE are inadequately informed about the possibilities of exercising (Sirven, 2009). Second, PWE have reported a fear of seizures and seizure-related injuries (Arida, Cavalheiro, da Silva, \& Scorza, 2008). Third, looking at the effect social support has upon a PWE's decision to exercise, Ablah et al. (2009) found that $68 \%$ of 412 surveyed epilepsy patients were actively discouraged by family members or another influence. As a consequence of this on-going hindrance, and despite the specific physical and mental benefits of physical activity, exercise is still not a regular occurrence for PWE (Dubow \& Kelly, 2003). The resultant inactivity levels have shown to contribute to social isolation, low selfesteem, weight gain, and depression for people with epilepsy (Pimental et al., 2015).

Narratives of everyday life for PWE have focused on the impact of epilepsy on quality of life, mental state, social support, and the side-effects of medication (Schachter, 2008). However, exercise has been noticeably absent. As a result of this limited source of qualitative research, I (Sarah), a sportsperson with epilepsy (SWE), published a three month autoethnography on running with epilepsy (Scarfe \& Marlow, 2015). This research provided 
first-person insight into the constant frustrations in the inability to have a consistent exercise routine and the fear of injury during exercise, which led to the loss of an athletic identity. Although this extended current knowledge of a SWE, it did not allow for multiple voices to be heard, nor show results over an extended time period. Therefore, through the use of narrative inquiry, we will explore the lives of three SWE (people with epilepsy who desires to exercise at least 3 times a week or would like to had they not been prevented by their epilepsy) over one year.

\section{Narrative inquiry}

Drawing from the recent development to expand methodology from positivistic or realist forms (Smith \& Sparkes, 2009a), narrative inquiry has provided an alternative methodological approach within current research. Describing narrative as a key process by which we construct, make sense, and relay our experiences, Smith and Sparkes (2009b) focused on how narratives allow people to communicate an experience. Concluding that every story is social as well as individual, Smith and Sparkes (2009a; 2009b) encourage the use of narratives as resources to encompass multiple viewpoints and circumstances of sportspeople. Furthering the idea of narratives as 'messy,' i.e. not fluid or constructed in regards to aesthetic presentation, they go on to discuss that human beings are messy, and therefore their narratives will reflect this.

Emphasising biographical time, the timeline over the course of one's life, as important within life story research, Sparkes and Smith (2003) focused on the effect time has on structuring a narrative. Throughout their research with men living with spinal cord injuries (SCI) within sport, biographical time was shown to affect the illness narrative, particularly as there was a change between a before and after injury identity. Viewing time as significant to narrative structure (Crossley, 2002), it is of importance to consider the effect of time within 
each SWE's experience. Differing to a SCI, it is epilepsy's hidden and unpredictable nature that can cause disruption for a SWE over time (Scarfe \& Marlow, 2015).

Applying the approaches of Frank (1995) and Lieblich, Tuval-Mashiach and Zilber (1998), we explored the exercise narratives of SWE. Exploring the narratives of cancer patients, Frank (1995) described three types of narratives; chaos, quest, and restitution. Within chaos narratives, an individual cannot see a way out of his/her misery, nor a hope for the future. Within the restitution narrative, one follows the plot of, "yesterday I was healthy, today I'm sick, but tomorrow I'll be healthy again"' (p. 77). The final narrative, quest, is described as a "hero's journey" (p.116), depicting the illness experience as an awakening, a purpose, a journey that starts with an illness and allows one to come to a new sense of selfreflection. Although Frank (1995) explored cancer patients' narratives, there are elements of similarity between a chronic illness, such as cancer, and epilepsy. For example, in epilepsy, there is the hope for controlled seizures and increased quality of life (Scarfe \& Marlow, 2015; Schachter, 2008). The role of hope can be shown to provide an element of restitution, chaos, and quest, and as a result, would make it an applicable reference in examining the narratives of SWE.

Although not specifically within illness, Lieblich et al. (1998) presented narrative structures (e.g., progressive, steady and decline) as a result of investigations over time, drawing attention to the factors involved with shifts in one's narrative and the patterns that develop in an individual's life story. For example, does their story steadily advance (progressive), stay the same (steady), or is there an overall decline in the individual's story (decline). These can be seen as basic movements within a narrative, yet there could be elements to cause shifts in the progression, in other words, various life experiences that could cause a change within the structure, resulting in wavy structures, e.g., trial and error (Lieblich et al., 1998). Using these narrative structures as aims of reference, we will present the holistic 
narratives of SWE, individuals who have elements of visibility and invisibility with their disorder, as well as daily disruptions due to uncontrolled seizures (Scarfe \& Marlow, 2015). Prior to discussing the methods used, narrative literature within health and exercise will be presented to highlight further potential parallels to others exercising with health concerns.

\section{Narratives within health and exercise}

Insights into the experiences of exercising with a chronic condition/illness have been shown to be an impactful way to present an individual's social construct (Moola et al., 2011; Smith, 2013). Smith (2013) presented ethnographic creative nonfiction narratives of individuals with SCI as a result of sport, highlighting the meaning of sport for the individual with SCI. These narratives provided empirical knowledge in a detailed and insightful manner, presenting the thoughts, feelings, and views of a newly impaired body. Presenting the variances between a chaotic view of their new body and its limitations on their previous lifestyle, to the view that this should not be the end to their sport lives, these narratives showed the impact of social interaction as a tool towards acceptance. Through presenting the narratives as social interaction, Smith (2013) advanced theoretical knowledge through emphasising the social aspects of narratives. Using narrative analysis to provide the social and cultural world of SWE, we are interested in portraying how epilepsy shapes the SWE's world. Differing to SCI, as epilepsy is a hidden disorder, these narratives will provide insight into the social narrative of how it is to exercise with epilepsy and the impact sport importance and his/her social world has upon the SWE's narrative.

Exploring narratives with older people and their sport uptake, Hudson, Day and Oliver (2015) presented narratives of positive personal change, as well as decelerated decline. Researching older individuals who were enrolled onto an exercise programme, one element that structured the progression of the individual's narrative was a sense of control. For 
example, within the narrative of positive personal change, individuals were shown to embrace a hope for the future and accept control over their health. Conversely, for individuals presenting the decelerated decline narrative, as they are not able to stop the aging process, an aspect of helplessness or lack of control concerning aging prevailed, thus limiting the longterm positive effects of the programme. As PWE have reported the feeling they have little control over how their epilepsy affects their life (Scambler, 1989), we are interested to understand how SWE view their locus of control and how this shapes their narrative.

A stigmatized disorder, the social and cultural representations of epilepsy (e.g. tonicclonic seizures, i.e. convulsive seizures, are the main manifestation, epilepsy is a mental illness, and one fears a person with epilepsy), can negatively impact a PWE's sense of selfperception (Scambler, 1989). Therefore, it is of interest to explore whether these representations also play a part in the formation of a SWE's narrative. Previous literature on youth with congenital heart disease (CHD) showed that exercise participation was impacted by their social and cultural world (Moola et al., 2011). Presenting narratives of realist and resistance, Moola et al. (2011) showed that within physical activity, some youth with CHD felt that physical activity emphasized the social and cultural representation of CHD as fragile, and struggled with barriers within physical activity (realist). However, other youth presented resistant narratives, challenging the social and cultural representation of being labelled as frail and not capable of what others could do. Although epilepsy narratives have shown aspects of this in everyday life (Schacter, 2008), it has yet to be explored through the cultural aspects of sport and exercise.

Through upholding social constructionist philosophy, our aim for this research is to use the context of a sporting environment to further the unknown views of the SWE, generating unique insight into the methods, motivations, and barriers of exercising for SWE over time. Within illness, social constructionists "emphasize how the meaning and experience 
of illness is shaped by cultural and social systems" (Conrad \& Barker, 2010, p.67). Using this framework to explore the SWE's experiences with exercise, we will portray the hows of the SWE narrative. It is through the participants' own words, pauses, and forgetful moments, that their disorder will be voiced with the aim of furthering medical and personal knowledge about the SWE (McGannon \& Smith, 2015). As shown in Lieblich et al. (1998), stories "shape and construct the narrator's personality and reality. The story is one's identity, a story created told, revised, and retold throughout life" (p. 7). Based on Frank's (1995) narrative work and Lieblich et al.'s (1998) narrative theory, the SWE's narratives were explored over the course of one year, showcasing the social and cultural world of the SWE. Documenting three SWE of various sporting level and seizure type, this research will allow those absent from present quantitative and medical literature to share their story and thus allow us to gain valuable knowledge into ways we may encourage and sustain exercise for SWE. Through using narrative inquiry, this research will explore the questions of how does a SWE narrate their experiences of exercising with epilepsy over time? What helps shape and deconstruct such narratives? How does the social world of the SWE affect their narrative? Lastly, what can we learn from witnessing the story of the SWE?

\section{Method}

Choosing to explore the lives of SWE through a narrative analysis, this research holds to the epistemological assumption that knowledge is constructed and subjective (Smith, Tomasone, Latimer-Cheung, \& Martin Ginis, 2014). Acknowledging that the narrative approach is method, theory, and methodology (Smith, 2013) the following will discuss the steps and narrative social constructionist theory of documenting the social and cultural narratives of SWE. 
Following ethical approval from the University of Roehampton Ethics Board, participants were recruited through the Epilepsy Action UK research database. There were three criteria for participants: 1) epilepsy was the participant's main condition; 2) age was 18 years and/or older; and 3) he/she exercised at least three times a week, or would do so, were they not hindered by their epilepsy. The criteria were set to ensure that sport was important to the participant, as well as a primary epilepsy diagnosis (Dubow \& Kelly, 2003). Sport type and seizure type were of no consequence to recruitment, however, in order to use these findings for comparisons within future research, each were noted. Pseudonyms were used to maintain participant anonymity.

\section{Interview Process}

Over the course of one year, I conducted four interviews, one every three to four months, with each participant. Following recruitment, verbal and written consent was obtained and the first interview conducted as soon as possible. The interviews were semistructured/conversational in order to get into a 'conversation' with the SWE, and took place in local coffee shops and interview rooms at the University of Roehampton. Drawing on Kvale and Brinkmann (2009), using phenomenological aspects in interviewing encouraged the exploration of the meaning and life world of the SWE. This was achieved by focusing on questions were focused on what and how, and not why (Smith \& Sparkes, 2009b). Each first interview began with a generic opening question, "Please could you describe your experiences of exercising with epilepsy?" Subsequent questions explored topics of exercise routine, social support in encouraging/preventing exercise, current barriers to exercise, as well as any coping mechanisms used to overcome those barriers. Further clarification of topics through follow-up questions allowed a rich detailed account within each interview. Background questions were also asked concerning family life, work, and basic demographic information. All questions for the subsequent interviews were developed through reflection 
whilst transcribing, general follow-up questions, as well as topics that I had experienced as a SWE and were absent from literature. Interviews varied in length depending on the participant, lasting an hour and a half to four hours. As a supplement to the four interviews, personal diaries were supplied to the participants to add depth to their lived experience (Dornelas, 2008). Participants were asked to write down any thoughts they had about their exercise experiences in connection to their epilepsy. These were not collected, but extracts of the diaries were often read aloud during the interview and are presented as italics within the narratives.

The desire for the researcher/participant relationship was that it should be one based on trust and rapport. This was initially built through early conversations via email and/or telephone, as well as from general chatting prior to recording of the interview. As they were willing to share their experiences, I was willing, where appropriate, to share my experiences as a SWE as well (Galvin, 2005). Similar personal entanglement was seen in Galvin (2005) and was shown to have a positive influence in the production of in-depth and exclusive access to information unbeknownst to current literature.

Reflection is an important methodological process within qualitative research, allowing for preconceptions to be acknowledged (Etherington, 2004). In order to recognise any researcher effect upon the interviews or compilation of the stories, multiple reflective steps were taken (Etherington, 2004). First, prior to commencing interviews, I conducted a self-interview (Langdridge, 2007), reflecting on any pre-conceptions such as; reactions to diagnosis, emotional response to lack of exercise, and living with seizures. The purpose of this self-reflexivity was not to become objective, but to increase my self-awareness of issues that may arise as a result of interviewing other SWE. Through this self-interview, I was able to acknowledge my own experience of exercising with epilepsy and how it could negatively 
and positively impact the interview and analysis process. Methods, such as discussions with my co-author, were subsequently put into place to limit any negative impact on the research process. Second, memo writing and maintaining a reflection journal provided an on-going resource for my own need to tell my story as I heard others'. In addition to these reflective methods, constant discussions with my co-author, provided a listening ear, as well as critique of both the analysis method and interpretation of the results (Hudson et al., 2015).

Developing a narrative through narrative analysis, one must remember that the researcher's story also contributes to the make-up of the narrative and how the participants' stories are interpreted (Alvermann et al., 1996). As researcher, although my words may not directly be shown within the narratives, I am present in the decisions to focus on various themes, as well as to shape the narratives in this fashion (Carless \& Sparkes, 2008).

\section{Narrative Analysis}

Through the use of narrative analysis, the social construction of the SWE's individual experience will be presented, resulting in shared knowledge and possibly, new social representations. Shaping the narratives through the position of story analyst (Smith \& Sparkes, 2009b), a holistic-content approach and a structural analysis were used to analyse the narratives (Carless \& Sparkes, 2008; Lieblich et al., 1998; Smith \& Sparkes, 2009b). A holistic-content approach views the "story as a whole, contextualized in a culture and history, and attempt(s) to grasp the overall pattern or guiding metaphors" (Bleakley, 2005, p.537). Further structural analysis focused on the way each participant's narrative was organised, for example, was it a hopeful story or one of on-going negativity (Smith \& Sparkes, 2009b). Using diachronic data, or data that related to temporal patterns or events (Oliver, 1998), structural analysis allowed for the stories to show distinct features of structure in which the narrative was formed (Smith \& Sparkes, 2008). Drawing upon parallels of other narrative 
research (Carless \& Sparkes, 2008; Hudson et al., 2015; Moola et al., 2011; Smith \& Sparkes, 2008), these narratives are shaped to convey the participant's story, thus presenting a deeper understanding of the SWE's world.

In order to provide the lived experience for the reader, the narratives were developed from the transcripts and diaries of the participants (Langdridge, 2007). Using health and sport narrative literature as a basis (Carless \& Sparkes, 2008; Frank, 1995; Lieblich et al., 1998; Smith \& Sparkes, 2009a; 2009b), a step-by-step analysis method was developed for each narrative. First, after each interview transcription, narrative analysis began with thematic coding, drawing out relevant themes within the text and making notes in the margins of each transcript. Second, the individual themes were organised into overall themes, for example exercise and epilepsy, seizure triggers, and social support. Once each theme was grouped into an overall theme, these were then ordered with regard to importance to the participant's story (Lieblich et al. 1998). Third, the transcript was re-read to make sure there were no other themes present. Fourth, a thematic map was created (Carless \& Sparkes, 2008), similar to a mind map, which displayed a visual diagram of the thematic connections. This provided visual clarity of consistent themes that were overarching of the story, as well as themes that may have changed over time. Last, structural analysis was conducted. Using a creative nonfiction analytical technique (Carless \& Sparkes, 2008), each narrative was created using an overall view of the present themes, and shaped to convey the participant's overall story to the reader. Conducting this final step multiple times, each segmented theme was organised in regards to its importance to the overall story, as well as fluidity in reading. As discussed earlier, the presentation of these narratives can be described as 'messy' and differs to previous literature (Frank, 1995; Smith \& Sparkes, 2008). To provide context for the reader, questions were integrated into the narratives, allowing the narratives to read as only participant speech (Carless \& Sparkes, 2008). The aim in providing narratives that have little 
to no academic interruptions was to tell the participants' story without outside context (i.e., researcher comments), thus creating a more storied representation. Aiming to present the constant thematic connections and influence of time within the narrative structure, these narratives follow the chronological sequence of the interview timeline and are developed to not read as a smooth story, but to present the constant shifts, changes, and bumps that occur in the exercise life of a SWE. Furthering this belief, Crossley (2000) explained that for narratives, one must attempt to preserve the essence of the individual and how their use of language or discourse form how the individual views and understands their world. Each narrative therefore acknowledges each participant's language, including when speech was hindered or problematic because of medication side-effects.

\section{Criteria for judgement}

In the use of narrative analysis, conventional judgement criteria cannot be used to fairly judge this research (Smith et al., 2014). Through considering appropriate criteria (Carless \& Sparkes, 2008; Lieblich et al., 1998), and upholding a social constructionist philosophy for judgement (McGannon \& Smith, 2015), the following are the suggested criteria to be used whilst reading these narratives. First, do these narratives make a substantial contribution to the greater understanding of psychosocial impact of epilepsy on the SWE's exercise life? Second, does the narrative formation provide a coherent and readable overall narrative? Third, have these narratives made an emotional and intellectual impact upon the reader? Finally, does the reading of these narratives promote extended discussion on the psychosocial impact of exercise on the SWE? Prior to presenting the narratives in which these criteria will be used, the participants' background information will be shown.

\section{Participants}


Gwen, in her late 30s, had been a track and field sprinter from a young age and was a self-described 'athlete'. She had always loved sport, however, after being diagnosed with complex partial seizures (CPS) at age 11, by age 13, the side-effects of her medication took its toll on her body, thus limiting her exercise routine. At the time of the first interview, Gwen participated in running, cycling, and went to the gym at least two times a week. Gwen's constant frustration with barriers to exercise was apparent throughout our discussions. Married to a supportive husband, Gwen acknowledged that it was hard seeing others exercise, when she could not do the same.

Rose was an active individual (exercising at least 3 times a week) in her mid-20s who enjoyed her after-work and weekend exercise routine. Being diagnosed with tonic-clonic seizures a year ago, Rose has only ever had two seizures. Feeling frustrated at her family and friends' lack of understanding of how her epilepsy impacted her life, she was drawn to this study in order to talk with someone about her concerns of exercising with epilepsy.

Andrew, in his mid-20s, was a rower and very eager to talk to someone else who had epilepsy. Having tonic-clonic seizures since the age of 18, Andrew seemed to be overly sensitive of others' opinions of him. As a club rower (exercising at least three times a week), Andrew had been steadily moving up the boat, becoming a stronger and stronger presence within the team. He became an even stronger presence when he had his first seizure during circuit training. His embarrassment and fear of what was to come in every training session had a negative effect on his exercise routine.

\section{Results}

Gwen's narrative- Vicious cycle: 
When seizures do happen, I know for a fact that the following day, maybe one or two days after, exercise is out! I cannot do any exercise 'cause I'm absolutely exhausted from them. So I feel like just as I'm getting into the scheme of doing my exercise two or three times a week, I feel like I'm back to square one. And it can be a whole week, week and a half without doing anything and I feel VEERY frustrated because... I do my best to really try and keep fit and I think, rather than me, my exercise dominating what I'm doing, it's my epilepsy that seems to be making my decisions when I can exercise. Which I find very, very frustrating.

Most of my seizures seem to be an indication, that I've overworked. It's almost as if my body's telling me, my brain's telling me, "You've done too much." Ummm... but yeah it's getting that kind of balance right between, listening to your body and recognising when a seizure will come on and whether you want to go to the gym... Just challenge, just challenge it and think, “Am I gonna go?”... I think my own way to encouraging that is by saying... “There's nothing I can do about it."

Three months later: There is a slight tenuous link, but I think it's a link nevertheless, in that, since I've been going swimming as opposed to running or going to the gym, it's really helpful to my seizures... It's better to do three lots of 30 minutes of a gentle swim, and I love it! ... 'Cause I feel, it's interesting because you'd think it's more dangerous to go swimming if you have a seizure. But to me, I just feel more... I don't know... I feel more in control, I feel more relaxed.... And I think that is really important because when I would go for a run or go to the gym, I could guarantee a seizure afterwards. But when I go swimming, I don't always get seizures.

Uh... maybe because I'm using myself in the exercise, in what I'm doing... I just think, "Take this lane" and whatever I'm doing in this space, emotionally, and I just go with 
what I have to do. And it's a really nice feeling that I'm kind of, just get in there and just do it and just enjoy the experience.

But there's a bit of a catch 22 to that because sometimes when my mind and my body goes to a relaxed state, then I'm more susceptible to seizures. Because I know when I'm really busy... at work, I NEVER have seizures, EVER! Because my mind is so focused. This is interesting 'cause when I was swimming, my mind is so focused, I never have any during that time.

(Diary entry) "I had another, further seizures yesterday, so my health won the battle and I was unable to go swimming. Felt a bit sad that my routine was messed up a little bit. Feels like a catch 22. When I know it's hard to swim, but going for a swim clearly helps me relax..." So, yeah, it can be a bit, I find it quite frustrating because I think, if I didn't have any seizures at all, I would be probably be swimming five days a week. I think, mentally, I've got the energy and motivation to do it. But just physically and medically, yeah whatever, it just buggers up my whole routine! And I just try to come to the realisation that that's just the way it's going to be.

Three months later: Umm, yeah, mixed bag. What can I say? Still having, it's quite weird, quite sporadic seizures... But I'm still trying to maintain as much of my exercise as possible. However, what I have noticed, the times where I have my clusters of seizures together, there's no way I can do any exercise, I can't do any. So I find it very, very, I think frustrating. And really, umm, just, I don't know, annoyed that I have the motivation to do it, but physically I'm just too exhausted and run-down...

... And then I had one yesterday in the morning, and I thought, "Be damned, I'm going swimming!” And I had a really good workout! I had one of the best workouts I've had... And I came out, and I was so pleased with myself for going, and I felt, psychologically, 
emotionally, and physically better for doing it. I'm just wondering if I could probably do it all the time...

But it is such a vicious cycle; it is such a vicious cycle. You know, you have to make a decision, an important decision if you want to break that cycle. And almost, take a bit of a risk if you've had a seizure. And just say, "Ok, gonna do this bit of exercise." Otherwise it's that cycle of if you have seizures, you can't exercise. If you can't exercise, that sometimes makes you feel a little bit low and frustrated, and that sometimes can make you feel run down and induce more seizures. And unless you break that cycle and start to exercise... I felt REALLY so much better for having doing it. So the cycle looks quite different! ... The trouble is that cycle isn't always predictable.

Four months later: It's been a bit up and down. Definitely... but in terms of exercise, it's (swoop down with hands) very low. And I've had a couple of moments, couple episodes, like weeks, where I was able to do my swim, do all my laps, and then I just had a series of seizures.... So yeah, exercise has dropped quite dramatically because my health has been worse off ... And it's been very frustrating!

I think as well, I am at the point now where I have to say, "You've just got to listen to your body. Your body's telling you don't do exercise, don't do exercise."... And all the effort you try to make it not dominate what you do. It's impossible for it not to.

Probably, the one point I want to get across is the frustration, the absolute frustration that your epilepsy has control over, deciding for you, the level of exercise you do. Rather than you being able to make that decision.

\section{Rose's narrative- Roller coaster}


It was a really, really difficult time when I first got diagnosed... Yeah, but I was on Topiramate $^{1}$ at first, for a while, but that just really didn't agree with me... The exercise thing sort of took a backseat... And as soon as I started taking Lamictal, ${ }^{2}$ I could see such a huge difference, it was like I was back to my old self.

In this past year when I have been feeling rubbish, I think exercise has been one of the things that... sort of helped me. Gives you some time to get out of your head a bit... I sort of see exercise as an outlet for feeling better. 'Cause, like, work's rubbish and I get to go after work. It's a bit of release... I go swimming with this friend, we go straight after work. It's just nice, I'm sure it's a mix of just chatting with my friend as well and the actual exercise, but I feel I don't got that in my head anymore. I feel a bit freer. And, it will make me, like at the time, I will feel better, feel bit more awake... and I never actually felt twitchy in my head during exercise. Well, I suppose actually the other day in the gym I did because I was really tired and felt like I was probably pushing myself too hard, so I stopped. Other than that, especially when I am running outside, I'd never feel that twitchy when I've been exercising...

Three months later: Well I've been doing a lot! I cycled from Coast to Coast in... April. So that was really good fun. So up to that, I was sorta doing a lot 'cause I was training for that for three months... Umm, and yeah, I do bits in between like I normally do really, swimming, running, but mostly biking cause I was training for this ride. I was a bit worried about it because it was sort of a long ride. It's 150 miles and we did it over 4 days. I was really looking forward to it, but I was a bit worried, “Oh, am I going to wear myself out?” ... But, when I was away, I wasn't aware of it (epilepsy) at all.

\footnotetext{
1 Anti-Epilepsy Drug (AED)

${ }^{2} \mathrm{AED}$
} 
I think what triggers my seizures is a different kind of tiredness. Like when you've been out on a bike all day, it's like physical tiredness, and then you sleep, don't you? I think, the tiredness that comes from not sleeping and being stressed and stuff, I think that's what triggers my... even if it's not a proper fit, but when I get sort of twitchy and things like that... I personally don't really associate seizures with exercise.

In terms of deciding to exercise, yeah I don't know. If I generally felt a risk that I'd have a seizure and felt a bit seizurey, I wouldn't go. Whereas if I didn't feel seizurey, I would go. ... I think in a way it's about finding a balance between being aware of it and thinking about it. Be responsible, but not let it take over your life...

It does get, sort of easier I suppose. I am weary, as well, that I need to keep it into consideration. I just can't let it go out of my head because then that's what happened last time I had a fit... You never notice, you don't know the trigger till it happens, do you? That's the thing. And even then, you have to go too far to know where too far is...

Four months later: I had a fit not long ago, 'bout the start of August. So yeah, bit unwell after that... So I was a bit, knocked out for like the whole week.

I had it while exercising. I was actually quite surprised I had it in the evening as well, 'cause I've only ever had them in the morning... so it was just a bit... a shock really... I went out for a run, in the evening with a friend. Was fine, doing fine... I was just running and talking and then it came on all of a sudden, like I was going to be sick, really sick! ... So I said to her, "Carry on, I'm just going to have a minute." And sort of got like down on the floor a bit, and that was it! That's all I remember. I kind of remember really wanting to lie down, and my friend being like, "Come on Rose, Rose.” I kinda remember lying down and her talking to me, but not being able to do anything about it. ... (pause) I think I had my eyes open 'cause I remember seeing her, but I couldn't, I couldn't, like I wasn't there. I don't 
think I was fitting at that point... Good thing actually that I was with a friend, 'cause if I was on my own, I don't know what I would have done.

I didn't really think of exercise, as a link. ... 'Cause it (medication) seemed to be working fine. I was quite surprised to be having one, to be honest. I thought the medication would sort it, so I probably was pushing myself a bit.

Yeah. It's a difficult thing, because exercise is something I enjoy and I don't... Like, running around where I live is really pretty. So when it affects something like that, what you enjoy.... it's a pain, isn't it? It's not nice....

I'd say having a seizure is a bit on my mind, just to the fact that the first time I went out I was a bit like, “Ooh” about it. Not to the point that I didn't want to go. And I was talking to my friend about it the other week, and you can't stop doing stuff, can you? You can't let it affect you. I mean how many times have I gone out for a run and it's not happened?! It's just one unlucky time, I suppose. But, I think I definitely will be a lot more conscious of it... I'm less likely to go out exercising on my own.

So many people choose not to exercise and I'm almost like, "Well you can! You can do it fine. You should go, you don't appreciate it.” ... It's so frustrating! I just want to do something that isn't affected! (little laugh) Which is, sort of, seems to be getting less and less.

Three months later: I've been coping with it (epilepsy) a bit better. I don't know if it's because I've gone through it before or generally things are more in place, like I don't have to deal with the medication, getting used to the medication... There hasn't been many peaks and troughs, it's just been kind of a constant thing.

Before I saw exercise as beneficial, whereas now I'm weighing the benefits against the possible consequences. ... I went on a bike ride yesterday morning and struggled a bit 
actually... And you know when you start pushing yourself and you start to feel a bit sick... and I've started connecting them a bit now. And you start to think, "Oh god, I feel a bit sick." And you know, you start to worry a bit about it. I'd be like, "Should I go on? Should I go back? It's not worth it.”... Umm, just generally a lot more anxious... I also probably don't enjoy exercising as much 'cause I'm getting anxious.

It almost feels like, if I stop it (epilepsy) letting me exercise, it's another thing, isn't it? Exercise is something that I enjoy, something for me, that not enough people probably do. But I don't want it stopping me doing it... A lot of people are a lot better at doing mind over matter. I think, in the past I was a lot better. I'd be like, "You can do it, push through, push through." But now, to me, pushing through it, the consequences have jumped slightly. It's something a lot bigger...

My epilepsy is not something I sort of forget about, it's always active in me, with taking medication twice a day, every day. It never goes, out of mind, regardless of how long it is since I've had a fit. ... I don't think it will ever be different, don't think it will ever change, but... have to get used to that.

\section{Andrew's narrative- Roller coaster}

Yeah, they kind of happen, umm, at our gym, we have two rooms. We have the room where you're on exercise bikes and sit-ups and what not, and then you've got the room where you're lifting weights and really going for it. We do both rooms, and there's 15 exercises in each room. Now, two years ago, you'd do that cycle twice... Coach came back to us and said, "I want us to be the best team in the country, we will do it, another routine, again." So, it's three times. And it's in that third point where I'm dying for a drink or dying for some food, it's half an hour later I've woken up and they've said, “Oh, you got to the final stage and you were three away from finishing, but um, you fell down." 
The last... four months I've had them, from... from exercise, yeah... Umm... what do I do? So, I still go to the gym sessions, but I sit out for the last session and just relax. And umm, for the benefit of everyone else, I mean, they get to carry on.

I've got training tomorrow night... It's the first session on the water in the evening so... nervous is a word that springs to mind. Saturday is fine, we're on the water all the time. But, this is the first one where it's after work. Like, work's quite, uh, stressful and, I don't know, we'll see how work affects it.... But, yeah, I want to be in that boat. I want to keep my spot. I want to give my $100 \% \ldots$ And the last couple of years I've taken my body seriously and taken my involvement seriously. I think that's why the club has taken me seriously, I have the ability. I just have this thing, this wall standing in my way, and they're helping me overcome it, which feels kind of nice.

Three months later: My neurologist decided that Keppra ${ }^{3}$ was giving me too many side effects and decided to give me Topamax and that's given me even worse side effects.... I don't know. I ... I don't know. I have no idea why... But I do know that drug has changed me.

I can't, it's just peaks and troughs, peaks and troughs.... This drug, stresses you out, it makes you quite angry and quite a little bit annoyed with things. And the neurologist said, "Don't get into situations where you can get stressful, so it's probably wise that, if you play sport, don't play physical sport." And so I said, "Do you want me to tell you what I do?" And she's like, "Go on then." I said, "I row." And she said, "How many people? What kind of rowing?" And I said, "Well there's 20 of us in a boat.” And she said, “Oh, I'll probably give it up." "What?! That's the one thing that made me positive and really made my life good and you're telling me to give it up?" ... Umm, football I had to give up because it's in (town) and travelling there and back is dangerous, so she said, "Give that up." Two things, sporty things 
in my life that I really looked forward to each week, three sessions a week, that I really liked, have completely disappeared.

I've quit the gym. I couldn't be bothered. I just thought "No." I didn't even want to bother, so I stopped cycling. My bike has now been in the shed and not been used for 3 months. Whereas 3 months ago, it was being used every day. Three months ago also falls in line with me starting this drug. Now has that placed some fear factor into it?... I don't know. Confidence is gone I guess. But, it's... all things that I have liked have all finished around the time that drug was introduced... I'm missing my sport...

Four months later: I saw an epilepsy nurse and she said, "Stress, just take it out on stuff that you like doing." SO, I came back from Christmas having seen my younger brother and he said, "Run! Run as much as you want, take it out. Stomp the floor! ... Every step you take, see the people that you don't like at work or see epilepsy written on the floor," and I've done it, and it's amazing! I put my favourite music on and I run.

Before, I could never run 2 miles, and now I'm running and doing it three, four times a week. Feels awesome! I'm trying to be as active as possible, and every time I do it, I'm taking those words my brother said... And, it seems to work... Tennis, I'm playing a lot more tennis as well, even though it's cold... And skipping a lot... Yeah, skipping rope. I skip proper boxing style... Uh, I'm going to start playing football again in the summer... When you say increase it... that's what I want to do ... It's an exciting time cause I, this time 2 years ago, I was severely depressed. Not wanting to do much. I had the dragon boating, but there was nothing much else. Not much stimulus in my life, external... I was sort of crazy, now I'm sort of pushing myself... and I wanted to do it just because I wasn't allowed to do my rowing. That's the other thing, I asked to go back into the rowing squad and they said, "Yeah, yeah, it 
will be fine"... I just want to go 6 months... a year without a seizure, first! Before I even go near the boat.

Three months later: February... when I saw you in February I hadn't had a seizure since December. And then, that continued through to... May? So, it was a really, really, big remission period. And... umm... and then I had one. And, it just put a downer on everything... I was getting a bit more confident in everything I was doing. I was running without telling people. I was doing a few more activities at home that I don't think I should have been doing, and... I really pushed it. I went for a run and came back, did loads of weights, did loads of press-ups, sit-ups. I've got one of those hanging chin-up bars, did that. Went for a mini-sprint run, came back and woke up in bed... Umm, all this side (left side of body) was completely dead. Really hurt. Shin, really swollen, massive cut down there. Umm, but this side of my head (opposite side) was really dead as well. So I must have fallen on that side, and went to that side...

Everyone said to carry on, I said "No." So everything went under the bed or in cupboards and shoes put away. I said, "I can't"... I got the games console out. (laughs)... And then, I phoned one of my brothers who lives further away and told him how low I was feeling and he... umm... he broke down on me and said, "I've never been there for you." ... So he's joined (laughs)... joined Epilepsy Action and he wants me and him to run the marathon next year. So he said, "You're not giving up on all your sports!"

And then, I realised what I was doing. I was sort of, closing the curtains to everything. And I thought, "No I can't do it. I need to get back out..." But it was just a REAL kick! When you go that amount of time and you think that's it. 
I'm beginning to get my confidence back... just started for a couple of weeks. I just feel so much better... My neurologist says, “It's good, keep doing it.”... I'm still doing the routine, but umm, cut down, slimmed.

Full stop, I think exercise... it helps... No, I wouldn't stop again... Don't think so. Difficult I think. It's obviously the emotional, what it does to you, when you're, how you're feeling when you go into those appointments, and the neurologist tells you certain things. I was expecting her to tell me certain things like, "You should..." But, if someone told me you should stop exercising 'cause you had one when you were doing a sit-up... I wouldn't. Because it is, you're confining yourself more and more. The walls are really pulled in and what else can you do?

I think exercise has got to be done or otherwise I go into a state of there's nothing else to do almost. Try to be active and if you're not, then, you work, rest, play video games like my neighbours, and just... boring... I think that's the patient's prerogative to take it by the grip, and grip it!

\section{Discussion}

Addressing the knowledge gap of the lived experience of SWE within literature, these narratives have communicated new insight into the continuous endeavour, frustrations, and successes of exercising with epilepsy as told by SWE over the course of one year of their lives. Using Frank (1995) and Lieblich et al. (1998) as a guide, we examined the resultant themes that were pertinent in each holistic story and presented the narratives of each participant. Although there were similarities to previous literature in regards to emotional portrayal over time (Frank, 1995; Lieblich et al., 1998), none seemed to accurately portray the holistic story of the participants. Comparing these results to other narrative literature within sport (Carless \& Sparkes, 2008; Moola et al., 2011; Smith, 2013), the development of 
new narratives may be the result of exploring an unknown disorder, thus providing access to individuals that have not yet been fully heard or understood. Next, the new narratives of vicious cycle (Gwen) and roller coaster (Rose and Andrew) will be explained further.

\section{Vicious Cycle}

The vicious cycle was Gwen's clearest narrative and evident throughout her year's documentation. Describing her experience with exercise as a "vicious cycle", this cyclical narrative was depicted through Gwen's initial desire to exercise and frustration at the lack of exercise caused by recurrent seizures, followed by an increase in seizures as a consequence of exercise, leading once again to a limited exercise routine. This then re-ignited the cycle of frustration and worry surrounding her lack of involvement in exercise. The constant upheaval and resultant frustration as a result of this cycle showed similarities to our previous research, which described experiences of persistent frustration as a result of exercise-induced seizures (Scarfe \& Marlow, 2015). However, through viewing this constant emotional toil over a longer period of time, Gwen's narrative confirms that this frustration can be on-going if one is living with uncontrolled seizures. Smith (2013) provided similar sentiments of anger at one's body and the subsequent limitations this incurs, however, there is a difference between epilepsy and chronic injury. Elements such as epilepsy's invisibility and inconsistency of everyday occurrence reveal that a chronic injury is not the same as uncontrolled epilepsy (Scarfe \& Marlow, 2015; Smith \& Sparkes, 2008). The hidden nature of epilepsy, until a seizure occurs, creates an increased frustration as she looks "healthy", yet is prevented from exercising as she would desire. The unknowing nature of whether or not a seizure will occur prevents Gwen from exercising and adds to her anger and frustration. This differs compared to most narrative health research (Moola et al., 2011; Smith \& Sparkes, 2008), and was a key component of creating the cyclical nature of her narrative. This introduction to the social and cultural aspect of a hidden disorder is of importance to consider, particularly as it created a 
heightened emotional impact for Gwen. The addition of a new narrative type of 'vicious cycle' was an exciting addition to narrative literature and would benefit from further research.

\section{Roller Coaster}

For Rose and Andrew, although differing in elements of their narrative storyline, each depicted components of a trial and error narrative i.e., a progression storyline with disruption to cause a shift to decline and then back up to progression (Lieblich et al., 1998). However, entitling their narratives as 'roller coaster' seemed more suitable to the overall holistic narrative, revealing the constant psychosocial and physical disruption that epilepsy can create for a SWE over time. As with vicious cycle, the rollercoaster narrative differs to previous literature because of the hidden nature of epilepsy (Hudson et al., 2015; Smith \& Sparkes, 2008). This resulted in a negative emotional and occasionally social response, subsequently increasing frustration as seizures interfered with their exercise life. As current epilepsy and exercise literature mainly focuses on the benefits and/or barriers to exercise (Sirven, 2009), this narrative extends the literature through providing detailed reasons over time of how aspects of living with epilepsy (e.g., medical advice, sport choice, medication, seizure frequency) increase barriers to exercise, as well as what may decrease these barriers (e.g., confidence, social support, seizure control).

\section{The importance of time in the story of a SWE}

It is important that the effect of time is accounted for in regards to the psychosocial and physical health of the SWE. For the participants, the ability to cope with uncontrolled seizures proved to be on-going, and although some had been diagnosed for over 20 years, this was still a daily battle to successfully exercise with their seizures. These narratives also show a glimpse into how social support could ease disruption for the SWE over time, as shown through the negative and positive encouragement from Andrew's social support network. As 
previous research shows time to be a factor in learning to adapt to exercising with epilepsy (Scarfe \& Marlow, 2015), further research should draw attention to the importance of a strong support system that may aid adaptation and acceptance of disruption to an exercise routine.

What have these narratives told us about the SWE?

The vicious cycle and rollercoaster narratives have shown the constant daily psychosocial impact of epilepsy on the SWE. As shown, seizure frequency, social support, and adaptation in sport choice seemed to be key factors in maintaining exercise habits as well as quality of life. Throughout each of the narratives, frustration was a key result of epilepsy's interference on the SWE and supports findings from Scarfe and Marlow (2015) which presented the continuous frustration and emotional undulations that can occur for a SWE. Similar to Moola et al. (2011), this frustration increased through the efforts of trying to resist the social representation of epilepsy. This was shown through fighting stigmatic views of their participation in sport as well as sometimes ignoring the full impact their epilepsy has on their lives. Increased frustration led to changing of sport, social isolation, lower mental state, anger, and increased anxiety and irritability about not being able to exercise when or how they so desired. This is an important topic for sport and exercise psychologists to consider. How can the SWE overcome this frustration and exercise? These narratives reveal that it may be through the process of acceptance of their body's limitations that a healthier mental and physical state can result. Over time, acceptance shifted and changed, and consequently, clear and fluid exercise stories did not emerge. Elements such as seizure frequency, sport choice, and social support all had a part to play in their acceptance, or lack thereof, in epilepsy's impact on their sporting lives. For sport and exercise psychologists, these are key factors to consider in helping SWE achieve a healthy mental and physical state. Further research should 
be aimed at understanding such effects and find ways to increase acceptance and adaptation in the SWE's exercise life.

\section{Conclusion}

Through the use of language (e.g., seizurey, twitchy, vicious cycle), time, and reflexive methods, narrative inquiry was shown to be an appropriate medium to present the SWE's world (McGannon \& Smith, 2015). As a result of these narratives, dialogue can now emerge to find ways of helping SWE successfully exercise, to teach medical and exercise professionals what barriers are present for the SWE, and to promote understanding for those who share in these experiences. Through reading these narratives, SWE will be able to realise that they are not alone and that their voice is represented. Although these narratives cannot be generalised, for every SWE is not the same, this research can now be moved forward to provide other SWE with a voice.

\section{Acknowledgements:}

We would like to thank the participants for being so open and willing to discuss their stories and Dr. Caroline Ellis-Hill who read a previous version of this paper. We would also like to thank Epilepsy Action UK who helped fund this research.

\section{References}

Ablah, E., Haug, A., Konda, K., Tinius, A. M., Ram, S., Sadler, T., \& Liow, K. (2009). Exercise and epilepsy: A survey of Midwest epilepsy patients. Epilepsy and Behavior, 14, 162-166. doi: 10.1016/j.yebeh.2008.09.019

Alvermann, D. E., O'Brien, D. G., \& Dillon, D. R. (1996). On writing qualitative research. Reading Research Quarterly, 31, 114-120. doi: 10.1598/RRQ.31.1.6 
Arida, R.M., Cavalheiro, E.A., da Silva, A.C., \& Scorza, F.A. (2008). Physical activity and epilepsy. Sports Medicine, 38(7), 607-615.

Aydemir, N., Vu Trung, D., Snape, D., Baker, G. A., \& Jacoby, A. (2009). Multiple impacts of epilepsy and contributing factors: Findings from an ethnographic study in Vietnam. Epilepsy \& Behavior, 16, 512-520. doi: 10.1016/yebeh.2009.09.005

Bleakley, A. (2005). Stories as data, data as stories: Making sense of narrative inquiry in clinical education. Medical Education, 39(5), 534-540. doi: 10.1111/j.13652929.2005.02126

Carless, D., \& Sparkes, A. C. (2008). The physical activity experiences of men with serious illness: Three short stories. Psychology of Sport and Exercise, 9, 191-210. doi: 10.1016/j.psychsport.2007.03.008

Conrad, P., \& Barker, K.K. (2010). The social construction of illness: Key insights and policy implications. Journal of Health and Social Behavior, 51, 67-69.

Crossley, M. L. (2002). Introducing narrative psychology. In: Narrative, memory, and life transitions (pp. 1-13). Huddersfield: University of Huddersfield.

Dornelas, E. A. (2008). Existential issues, heart transplant, and end-stage cardiac disease. In E. A. Dornelas (Ed.), Psychotherapy with Cardiac Patients: Behavioral Cardiology in Practice. (pp. 141). Washington D.C.: American Psychological Association.

Dubow, J.S., \& Kelly, J.P. (2003). Epilepsy in sports and recreation. Sports Medicine, 33(7), 499-516.

Etherington, K. (2004). Becoming a Reflexive Researcher. London: Jessica Kingsley Publishers.

Frank, A. W. (1995). The wounded storyteller: Body, illness, and ethics. Chicago: University of Chicago Press.

Galvin, R. D. (2005). Researching the disabled identity: Contextualising the identity transformations which accompany the onset of impairment. Sociology of Health and Illness, 27(3), 393-413. 
Hudson, J., Day, M.C., \& Oliver, E.J. (2015). A 'new' life story or delaying the inevitable? Exploring older people's narratives during exercise uptake. Psychology of Sport and Exercise, 16, 112-120.

Kvale, S., \& Brinkmann, S. (2009). Interviews: Learning the craft of qualitative research interviewing. Los Angeles: Sage.

Langdridge, D. (2007). Phenomenological psychology: Theory, research, and methods. Harlow, England: Pearson Education Limited.

Lieblich, A., Tuval-Mashiach, R., \& Zilber, T. (1998). Narrative research: Reading, analysis and interpretation. London: Sage.

McGannon, K.R., \& Smith B. (2015). Centralizing culture in cultural sport psychology research: The potential of narrative inquiry and discursive psychology. Psychology of Sport and Exercise, 17, 79-87. doi: 10.1016/j.psychsport.2014.07.010

Moola, F., Fusco, C., \& Kirsh, J.A. (2011). "What I wish you knew": Social barriers toward physical activity in youth with congenital heart disease (CHD). Adapted Physical Activity Quarterly, 28, 56-77.

Oliver, K. L. (1998). A journey into narrative analysis: A methodology for discovering meanings. Journal of Teaching in Physical Education, 17, 244-259.

Pimental, J., Tojal, R., \& Morgado, J. (2015). Epilepsy and physical exercise. Seizure, 25, 8794.

Scambler, G. (1989). The Experience of Illness: Epilepsy. London: Routledge.

Scarfe, S.V., \& Marlow, C. (2015) Overcoming the fear: An autoethnographic narrative of running with epilepsy. Qualitative Research in Sport, Exercise, and Health, 7(5), 688697. doi:10.1080/2159676X.2015.1035741

Schachter, S. C. (2008). Epilepsy in our view: Personal accounts of living with seizures. New York: Oxford University Press. 
Sirven, J. I. (2009). Epilepsy and exercising: Another brick in the wall? Epilepsy \& Behavior, 14, 1-2. doi: 10.1016/j.yebeh.2008.10.008

Smith, B. (2013). Sporting spinal cord injuries, social relations, and rehabilitation narratives: An ethnographic creative non-fiction of becoming disabled through sport. Sociology of Sport Journal, 30, 132-152.

Smith, B., \& Sparkes, A. C. (2008). Changing bodies, changing narratives and the consequences of tellability: A case study of becoming disabled through sport. Sociology of Health and Illness, 30(2), 217-236. doi:10.1111/j.1467-9566.2007.01033

Smith, B., \& Sparkes, A. C. (2009a). Narrative inquiry in sport and exercise psychology: What can it mean, and why might we do it? Psychology of Sport and Exercise, 10, 1-11. doi:10.1016/j.psychsport.2008.01.004

Smith, B., \& Sparkes, A. C. (2009b). Narrative analysis and sport and exercise psychology: Understanding lives in diverse ways. Psychology of Sport and Exercise, 10, 279-288. doi: 10.1016/j.psychsport.2008.07.012

Smith, B., Tomasone, J.R., Latimer- Cheung, A.E., Martin Ginis,, K.A. (2014) Narrative as a knowledge translation tool for facilitating impact: Translating physical activity knowledge to disabled people and health professionals, Health Psychology, 34(4), 303313. doi:10.1037/hea0000113

Sparkes, A.C., \& Smith, B. (2003). Men, sport, spinal cord injury and narrative time. Qualitative Research, 3, 295-320. doi: 10.1177/1468794103033002 